\title{
Deactivation and reactivation of the inhibitory power of a conditioned inhibitor: Testing the predictions of an attentional-associative model
}

\author{
Munir Gunes Kutlu • Nestor A. Schmajuk
}

Published online: 14 September 2011

(C) Psychonomic Society, Inc. 2011

\begin{abstract}
An attentional-associative model (Schmajuk, Lam, \& Gray Journal of Experimental Psychology: Animal Behavior Processes, 22, 321-349, 1996) assumes that nonreinforced presentations of an inhibitory conditioned stimulus (CS) do not decrease its inhibitory associations. However, the model predicts that extended presentations will decrease attention to the inhibitor, thereby decreasing both (1) the expression of its inhibitory power in a summation test and (2) the rate of acquisition in a retardation test. The model also predicts that subsequent presentations of the inhibitory CS with a novel CS will increase both (1) and (2). Using a predictive learning design in humans, Experiment 1 examined the predictions involving the summation tests, whereas Experiments 2 and 3 examined the predictions involving the retardation tests. Experimental results were in agreement with the predictions of the model.
\end{abstract}

Keywords Attention - Inhibition · Extinction .

Reinstatement $\cdot$ Attentional-associative model

In an early test of the Rescorla and Wagner (1972) theory, Zimmer-Hart and Rescorla (1974) used a summation test to evaluate the model's prediction that repeated presentations of an inhibitory conditioned stimulus (CS) would result in the elimination of its inhibitory power. The fact that they found the prediction to be incorrect, in addition to Baker's

We thank Raul Marquez for his help in running the experiments and Gonzalo de la Casa for his helpful comments.

M. G. Kutlu • N. A. Schmajuk $(\bowtie)$

Department of Psychology and Neuroscience, Duke University, Durham, NC 27708, USA

e-mail: nestor@duke.edu
(1974) report that presentation of an inhibitor together with a neutral stimulus did not convert the neutral stimulus to an excitor, prompted changes in later theories (McLaren, Kaye, \& Mackintosh, 1989; Schmajuk, Lam, \& Gray, 1996; Wagner, 1981; Zimmer-Hart \& Rescorla, 1974, p. 844) to avoid those inaccurate predictions.

Schmajuk et al. (1996) offered an attentional-associative model of classical conditioning (the Schmajuk, Lam, \& Gray [SLG] model) that assumes that, unlike excitatory associations, inhibitory associations do not extinguish by presenting the inhibitory CS alone. In the present study, we tested the model's prediction that repeated nonreinforced presentations of an inhibitory CS would decrease attention to that CS. In turn, this decreased attention would (1) decrease the expression of the inhibitory power of the CS in a summation test and (2) increase retardation when the CS is conditioned. Furthermore, we also tested the model's prediction that increasing attention to the CS by presenting it with a novel CS would reinstate its inhibitory properties measured in a summation test but, simultaneously, would decrease retardation.

The present article contributes to a number of apparently conflicting studies on the effects of extinction treatments on conditioned inhibitors. Whereas some reports (e.g., Zimmer-Hart \& Rescorla, 1974) have found no effect, others (e.g., Williams, Travis, \& Overmier, 1986) have reported increased inhibition in a summation test. Interestingly, Pearce, Nicholas, and Dickinson (1982) showed that extinction of a conditioned inhibitor results in no change in its inhibitory properties in a summation test, but they reported increased retardation during reconditioning, when compared with a group that received only context presentations. The Discussion section shows how the model addresses these conflicting results, thereby confirming the general validity of our analysis. 


\section{The attentional-associative model}

The SLG model (1996) presented an attentional-associative model of classical conditioning. The model incorporates (1) a mechanism that modulates attention to the $\mathrm{CS}$ in proportion to the total novelty detected in the environment and (2) a network that forms CS-CS and CSunconditioned-stimulus [US] excitatory and inhibitory associations, according to a real-time competitive rule. The model assumes that total novelty increases when (1) a predicted CS or predicted US is absent or (2) an unpredicted CS or unpredicted US is present.

Figure 1 shows a simplified diagram of the model that illustrates the different mechanisms involved in the generation of a conditioned response (CR) when a given CS is presented. Node 1 receives input from a short-term memory trace of the $\mathrm{CS}, \tau_{\mathrm{CS}}$, and the prediction of that $\mathrm{CS}, \mathrm{B}_{\mathrm{CS}}$, by other CSs or the context $(\mathrm{CX})$. In order to modulate attention to the $\mathrm{CSs}, \mathrm{z}_{\mathrm{CS}}$, in proportion to the novelty detected in the environment, the output of Node $1\left(\tau_{\mathrm{CS}}+\right.$ $\mathrm{B}_{\mathrm{CS}}$ ) becomes associated in Node 2 with the normalized value of the total novelty detected in the environment, Novelty'. Novelty' is computed as the sum of the absolute value of the differences between expected and actual magnitudes of each CS and the US. Since it is a function of Novelty', attention $\mathrm{z}_{\mathrm{CS}}$ increases when Novelty' increases, because (1) the target CS is not well predicted by the CX, other CSs (like Wagner's, 1981, SOP model), or itself (or equivalently, its elements do not predict each other, as suggested by McLaren \& Mackintosh, 2000, 2002), or (2) the target CS does not predict well the presence or the absence of other CSs or the US (which extends Pearce \& Hall's, 1980, basic concept).

Node 3 receives input from Node 2, the internal representation of the $\mathrm{CS}, \mathrm{X}_{\mathrm{CS}} \sim\left(\tau_{\mathrm{CS}}+\mathrm{B}_{\mathrm{CS}}\right) \mathrm{z}_{\mathrm{CS}}$, as well as from the error term, (US - $B_{U S}$ ). The synaptic weight connecting Node 2 to Node $3, \mathrm{~V}_{\mathrm{CS}-\mathrm{US}}$, reflects the (excitatory or inhibitory) association of $\mathrm{X}_{\mathrm{CS}}$ with the US. Changes in $\mathrm{V}_{\mathrm{CS}-\mathrm{US}}$ are proportional to (1) the magnitude of $\mathrm{X}_{\mathrm{CS}}$; (2) a common error term (US - $\mathrm{B}_{\mathrm{US}}$ ) that reflects the difference between the predicted value, $B_{U S}$, and the real value of the US; and (3) an individual error term (not represented in Fig. 1) that establishes positive and negative limits for the $\mathrm{V}_{\mathrm{CS}-\mathrm{US}}$ association. Importantly, in order to accommodate the Zimmer-Hart and Rescorla (1974) and Baker (1974) results, and along with Zimmert-Hart and Rescorla's suggestion, the model assumes that the term $\mathrm{B}_{\mathrm{US}}$ equals 0 when $\mathrm{B}_{\mathrm{US}}<0$, which implies that an inhibitory CS presented in the absence of the US will not change its $\mathrm{V}_{\mathrm{CS}-\mathrm{US}}$ association. Finally, the conditioned response $(\mathrm{CR})$ is a nonlinear function of the output of Node $3, \mathrm{~B}_{\mathrm{US}}=\mathrm{X}_{\mathrm{CS}} \mathrm{V}_{\mathrm{CS}-\mathrm{US}}$.

\section{Summation test}

Pavlov (1927) proposed that in order to determine whether a CS had become inhibitory after being presented with an excitatory CS in the absence of the US, the inhibitory CS should pass a summation test. A summation test consists of presenting the putative inhibitor with a conditioned excitor, with the expectation that the inhibitory CS will reduce the strength of the CR to the excitatory CS. Passage of the summation test excludes the possibility of a configural interpretation by which a compound of the inhibitory CS with the original excitatory CS is formed that predicts the absence of the US.

The model describes the $\mathrm{CR}$ in a summation test as a function of the prediction of the US,

$\mathrm{B}_{\mathrm{US}}=\mathrm{X}_{\text {Excitor }} \mathrm{V}_{\text {Excitor-US }}-\mathrm{X}_{\text {Inhibitor }} \mathrm{V}_{\text {Inhibitor-US }}$,

in which the strength of $\mathrm{B}_{\mathrm{US}}$ is determined by the difference between the associative value of the excitor $V_{\text {Excitor-Us }}$

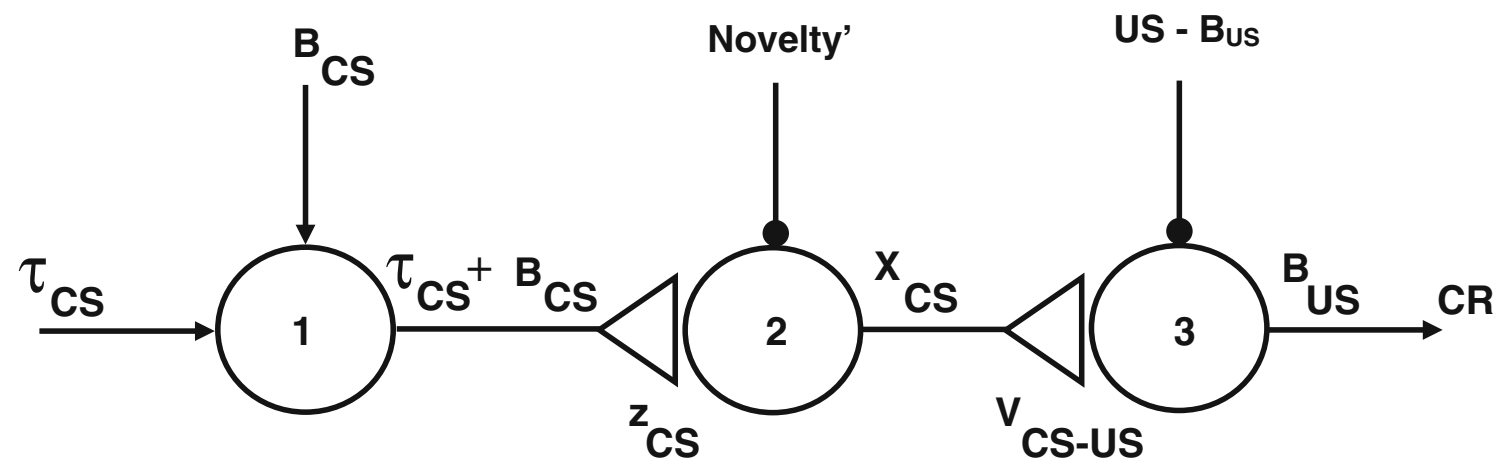

Fig. 1 A simplified diagram of the SLG model. CS, conditioned stimulus; US, unconditioned stimulus; $\tau_{\mathrm{CS}}$, trace of the $\mathrm{CS} ; \mathrm{z}_{\mathrm{CS}}$, attention to the CS; $\mathrm{X}_{\mathrm{CS}}$, internal representation of the CS; $\mathrm{V}_{\mathrm{CS}-\mathrm{US}}$, CS-US association; $\mathrm{B}_{\mathrm{US}}$, prediction of the US; (US - $\mathrm{B}_{\mathrm{US}}$ ), common error term; $\mathrm{CR}$, conditioned response. Triangles: variable connections (associations) between nodes that modulate the activation of the node. Arrows: inputs that control the output of the node. Solid circles: inputs that modify connections $\mathrm{z}_{\mathrm{CS}}$ and $\mathrm{V}_{\mathrm{CS} \text {-Us }}$ without affecting outputs $\mathrm{X}_{\mathrm{CS}}$ and $\mathrm{CR}$ 
activated by its representation, $\mathrm{X}_{\text {Excitor }}$, and associative value of the inhibitor $\mathrm{V}_{\text {Inhibitor-US }}$ activated by its representation, $\mathrm{X}_{\text {Inhibitor }}$.

\section{Retardation test}

In addition to summation, Rescorla (1969) suggested that a retardation test was also necessary to behaviorally determine the inhibitory power of a CS. He claimed that the summation test cannot exclude the possibility that the inhibitory CS modifies attention to the excitatory CS, thereby attenuating $\mathrm{B}_{\mathrm{US}}$ and the $\mathrm{CR}$. Such a possibility is rejected by the retardation test, which consists of conditioning the inhibitory CS, with the expectation that it takes longer to become excitatory than does a neutral CS. Note that a latent inhibitor would also pass a retardation test but not a summation test. Therefore, it is generally accepted that passing both the summation and the retardation tests would confirm the inhibitory power of a given CS.

A retardation test measures the strength of the CR achieved after a certain number of continuously or partially reinforced trials is given to a CS. The model describes changes in the conditioned-inhibitor-US association by

$$
\begin{aligned}
\mathrm{dV}_{\text {Inhibitor-US }} / \mathrm{dt}= & \mathrm{K}_{7} \mathrm{X}_{\text {Inhibitor }}\left(\mathrm{US}-\mathrm{B}_{\mathrm{US}}\right) \\
& \times\left(1-\left|\mathrm{V}_{\text {Inhibitor-US }}\right|\right) .
\end{aligned}
$$

According to the model, and in agreement with Rescorla's (1969) view, retardation can be the consequence of (1) the initial negative value of the $V_{\text {Inhibitor-US }}$ inhibitory association or (2) a small value of $X_{\text {Inhibitor }}$ following repeated presentations of the inhibitory CS (like a preexposed CS in latent inhibition).

A detailed mathematical description of the model is found in Schmajuk et al. (1996). Parameter values used in this article are identical to those used in Schmajuk and Larrauri (2006), Schmajuk, Larrauri, and LaBar (2007), and Larrauri and Schmajuk (2008).

As is explained below, the model predicts that (1) extended presentations of the inhibitory CS alone will reduce $\mathrm{X}_{\text {Inhibitor }}$ and its inhibitory power in a summation test and will increase its potential to pass a retardation test, and (2) subsequent presentations of the inhibitory CS with a novel CS will increase $X_{\text {Inhibitor }}$ and reverse its behavior in both tests. Three experiments tested these predictions using a predictive learning design in humans.

\section{Experiment 1: Summation tests following extinction and recovery of a conditioned inhibitor}

As was mentioned, because the model assumes that the term $\mathrm{B}_{\mathrm{US}}$ equals 0 when $\mathrm{B}_{\mathrm{US}}<0$, an inhibitory $\mathrm{CS}, \mathrm{X}$, presented in the absence of the US does not change its $\mathrm{V}_{\mathrm{X} \text {-US }}$ association (see Eq. 2). However, when attention $\mathrm{z}_{\mathrm{X}}$ and $X_{X}$ decrease, the action of the excitatory or inhibitory association $\mathrm{V}_{\mathrm{X}-\mathrm{US}}$ on Node 3 also decreases. Therefore, the model predicts that even if the inhibitory $\mathrm{V}_{\mathrm{X} \text {-US }}$ association does not change in the absence of the US, the inhibitory effect of $X$ in a summation test will (1) first increase when Novelty' and $X_{X}$ increase, when the original excitor $\mathrm{CS}_{\mathrm{A}}$ is predicted by $\mathrm{V}_{\mathrm{X}-\mathrm{A}}$ associations but is not present, and (2) then decrease with extended presentations of $\mathrm{X}$ because Novelty' and $\mathrm{X}_{\mathrm{X}}$ decrease, when $\mathrm{V}_{\mathrm{X}-\mathrm{A}}$ associations extinguish and $\mathrm{A}$ is not present.

Also, according to the model attention $\mathrm{z}_{\mathrm{X}}$ and $\mathrm{X}_{\mathrm{X}}$ increase when Novelty' increases as a consequence of the inhibitory X predicting the presence of another CS when that other CS is absent. Therefore, the model predicts that after extended nonreinforced presentations, presenting an inhibitory $\mathrm{X}$ with a novel $\mathrm{CS}_{\mathrm{N}}$ before testing will increase attention to $X$ when (1) the inhibitory $X$ is presented together with the novel $\mathrm{N}$ and (2) the inhibitory $\mathrm{X}$ is later tested in the absence of $N$. The increased $X_{X}$ will result in a reinstated inhibition in a summation test. These predictions will be tested in Experiment 1.

In order to confirm the validity of the above-described informal derivations from the model, formal simulations were conducted. Simulations consisted of $10 \mathrm{~A}+, 10 \mathrm{AX}-$, and $10 \mathrm{~B}+$ intermixed trials, followed by a first batch of tests of BX or BZ, in which $\mathrm{Z}$ is a novel CS. Following the first summation tests, simulations in the extinction/recovery (EXT/REC) and in the extinction/no-recovery (EXT/ NOREC) conditions consisted of $75 \mathrm{X}$ - trials and $10 \mathrm{G}+$ trials, and simulations in the no-extinction/recovery (NOEXT/REC) condition consisted of $75 \mathrm{Y}-$ trials and $10 \mathrm{G}+$ trials. The second batch of tests included presentations of GX or GW (in which $\mathrm{W}$ is another novel CS). Following the second summation tests, both EXT/REC and NOEXT/REC conditions received $3 \mathrm{XN}$ nonreinforced trials and $5 \mathrm{H}+$ trials, and the third test was conducted using $\mathrm{HX}$ or $\mathrm{H}$ with a novel CS, R, whereas the EXT/NOREC condition received $3 \mathrm{ML}$ nonreinforced trials and $5 \mathrm{H}+$ trials, and the third summation test was conducted using $\mathrm{HX}$ or $\mathrm{H}$ with a novel CS, R. Simulations for each group included different excitors (B, $\mathrm{G}$, and $\mathrm{H})$ that were tested paired with (1) $\mathrm{X}$ or (2) an external inhibitor (Z, W, and R) after each of the phases of the experiment: acquisition (BX vs. BZ), extinction (GX vs. GW), and recovery (HX vs. HR).

The saliences of the 20 time unit (t.u.) CSs were 1; the US strength was 1 , and its duration was 5 t.u., overlapping with the last 5 t.u. of the CSs. The salience of the CX was 0.1 , and the ITI was 1,500 t.u. The same results were obtained with a large range of different simulation values, such as CS, US durations, ITI, CS, US saliences, and trial numbers. 
As is shown in the upper left panel of Fig. 2, a simulation for the EXT/REC condition reveals that the inhibitory power of $\mathrm{X}$ in a summation test (as compared with that of an external inhibitor) (1) is strong after $\mathrm{A}+$ / AX- acquisition and (2) is eliminated following $\mathrm{X}-$ presentations, but (3) is reinstated after presentations of $\mathrm{X}$ with a novel stimulus N. The upper middle panel of Fig. 2 shows that a simulation for the NOEXT/REC condition reveals that the inhibitory power of $\mathrm{X}$ does not change following $\mathrm{Y}-$ presentations but increases slightly after presentations of $\mathrm{X}$ with a novel stimulus N. Finally, the right panel of Fig. 2 shows that a simulation for the EXT/ NOREC condition reveals that the inhibitory power of $\mathrm{X}$ (1) decreases after $\mathrm{X}$ - presentations but (2) does not change following nonreinforced presentations of two novel CSs, $\mathrm{M}$ and $\mathrm{L}$ (instead of presentations of $\mathrm{X}$ with a novel stimulus $\mathrm{N}$ ).

Figure 3 shows that the model explains these results in terms of the decreasing values of $\mathrm{X}_{\mathrm{X}}$ during $\mathrm{X}$ - presentations in the EXT/REC and EXT/NOREC conditions, but not during $\mathrm{Y}$ - presentations in the NOEXT/REC condition. For the EXT/REC and NOEXT/REC conditions, $\mathrm{X}_{\mathrm{X}}$ increases when Novelty' increases when (1) the novel $\mathrm{CS}_{\mathrm{N}}$ is presented with $\mathrm{X}$ and (2) then when the novel $\mathrm{CS}_{\mathrm{N}}$ is absent during the respective summation tests. Instead, in the EXT/NOREC condition, $\mathrm{X}_{\mathrm{X}}$ does not change during the presentations of $\mathrm{M}$ and $\mathrm{L}$ because $\mathrm{X}$ is not present during these trials. Figure 3 also shows that the $\mathrm{V}_{\mathrm{X}-\mathrm{US}}$ association remains inhibitory and unchanged after the acquisition phase.

In sum, the model expects $z_{X}$ and $X_{X}$ to decrease during $\mathrm{X}$ nonreinforced trials in the EXT/REC condition, thereby decreasing the inhibitory power of conditioned inhibitor $\mathrm{X}$ in a summation test. In addition, the model also expects that the decreased $\mathrm{z}_{\mathrm{X}}$ and $\mathrm{X}_{\mathrm{X}}$ can be increased again as $\mathrm{X}$ is paired with a novel $C S$, and therefore, the decreased inhibitory power of $\mathrm{X}$ can be reactivated in the EXT/REC condition, but not in the EXT/NOREC condition. In the NOEXT/REC condition, $\mathrm{z}_{\mathrm{X}}$ and $\mathrm{X}_{\mathrm{X}}$ increase when $\mathrm{X}$ is paired with a novel $\mathrm{CS}$ and further activates the inhibitory $\mathrm{V}_{\mathrm{X}-\mathrm{US}}$.
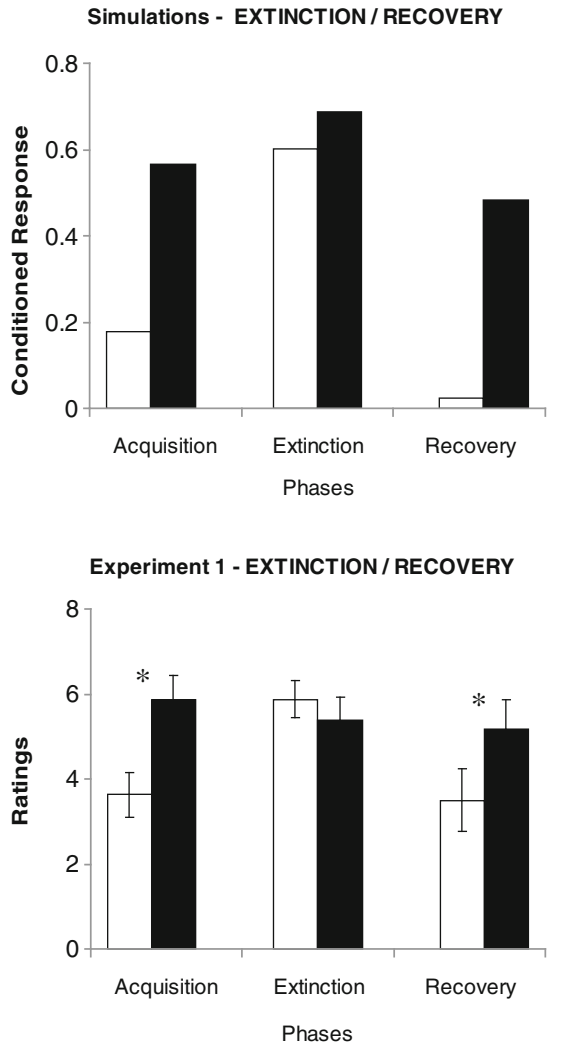
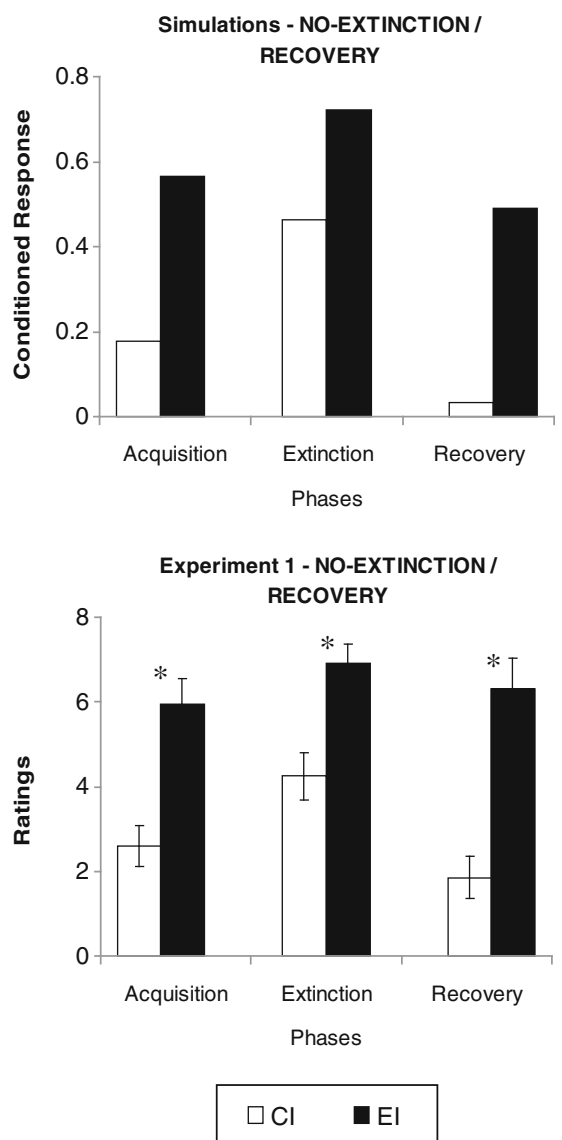
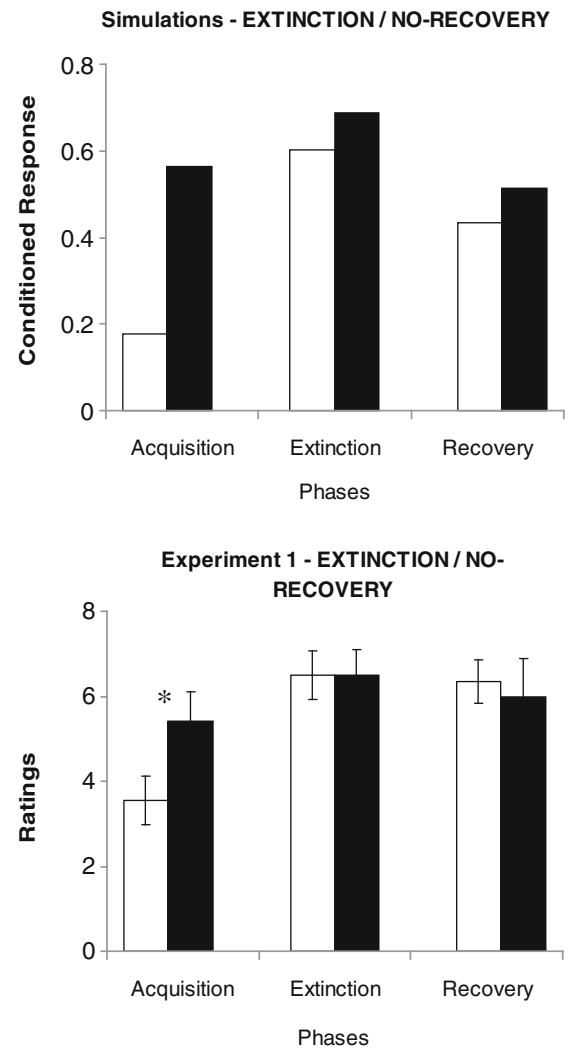

Fig. 2 Experiment 1: Responses in conditioned inhibition (CI) and external inhibition (EI) groups in three summation tests following acquisition, extinction, and recovery. Upper panels: Simulated conditioned responses. Lower panels: Experimental ratings. Left panels: Extinction/recovery condition. Mid panels: No-extinction/ recovery condition. Right panels: Extinction/no-recovery condition. Asterisks indicate a significant difference at the level of $p<.05$. Error bars show standard error of the mean (SEM) 
Fig. 3 Variables in the SLG model: Internal representations of $\mathrm{X}, \mathrm{X}_{\mathrm{X}}$ (upper panels), and association $\mathrm{V}_{\mathrm{X} \text {-US }}$ (lower panels) values during three phases of the simulations, acquisition, extinction, and recovery, for EXT/REC, NOEXT/REC, and EXT/ NOREC groups
Internal Representation of $\mathbf{X}\left(\mathbf{X}_{\mathrm{X}}\right)$

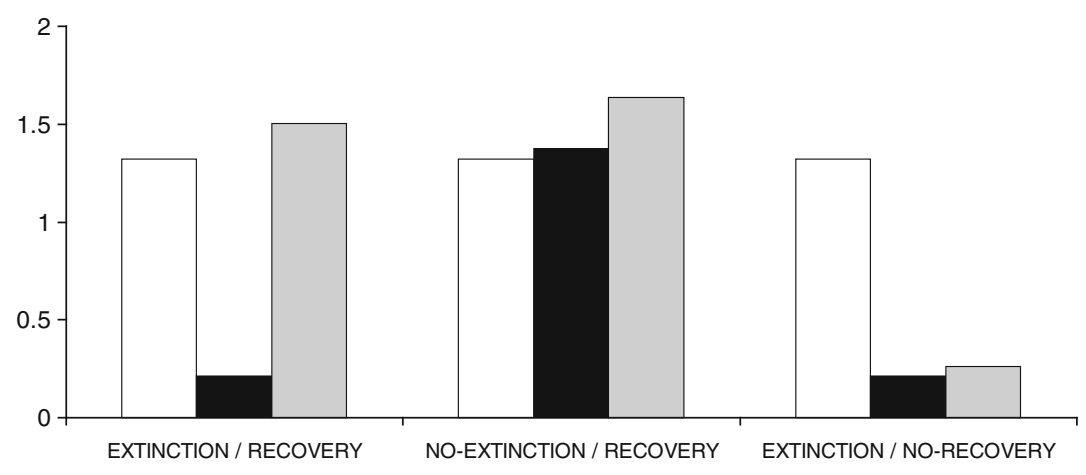

Associations $\mathrm{X}$-US ( $\left.\mathrm{V}_{\mathrm{X} \text {-US }}\right)$

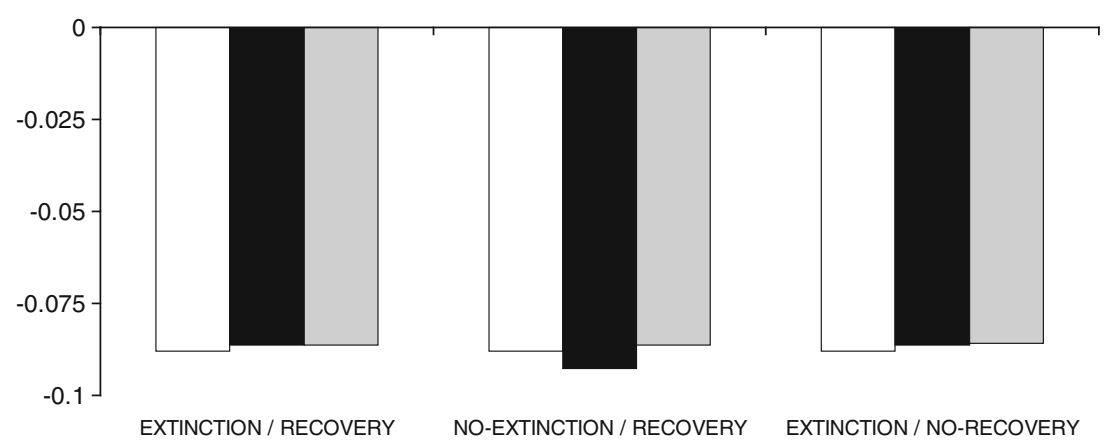

In order to test the above predictions, Experiment 1 studied the effect in summation tests of (1) A+/AXalternated presentations, (2) nonreinforced presentations of $\mathrm{X}$, and (3) presenting $\mathrm{X}$ with a novel $\mathrm{CS}_{\mathrm{N}}$. Our experiments used a human predictive learning paradigm similar to the one previously used by Karazinov and Boakes (2004) to obtain conditioned inhibition.

\section{Method}

Participants The participants were 120 (40 in each of three conditions) Duke University undergraduate students who did not participate in any subsequent experiment in this study. Participants were randomly assigned to six experimental groups. Data from 2 of the participants were eliminated due to a program error, and data from 8 participants were eliminated because they failed to meet the learning criterion (see below for details). Ten new participants were then added to complete the groups. Their participation was rewarded with course credits. Participants required approximately $15 \mathrm{~min}$ to complete the experiment.

Apparatus and stimuli Each individual was seated in front of a PC and was tested individually. A custom-made MATLAB
6.5.2 program was used for the cue presentations and obtaining the participants' responses. The participants used a regular PC keyboard to assign their responses. Thirteen different symbols from Microsoft Word $(\Omega, \phi, \partial, \xi, \approx, \omega, \#$, $\bullet, *, \S, \mathbb{\mathbb { 1 }}, \infty, \otimes)$ were used as stimuli. We counterbalanced the role of conditioned inhibitors between different symbols.

Design and procedure Each trial in the experiment consisted of two separate response and outcome screens. Response screens (500*450 pixels) contained 1 or 2 symbols $(270 \times 280$ pixels, centered on the screen $)$ and two buttons (at the bottom of the screen) labeled as "High Bar-'H' key" and "Low Bar-'L' key." The participants were asked to assign their responses by pressing one of the keys on the keyboard. As soon as one key was pressed, the outcome screen $(500 * 450$ pixels) appeared, in which the symbols were still present but no response buttons were shown. Instead, either a high red bar (67 pixels wide and 467 pixels high) indicating the presence of an outcome or a very low red bar (67 pixels wide and 10 pixels high) indicating a negligible outcome was presented on the right side of the screen. While the response screen stayed on for an unlimited time, the outcome screen was on for only $2 \mathrm{~s}$, and there were no time gaps between screen presentations. 
The experiment was divided into three phases: acquisition, extinction, and recovery (see Table 1). After each phase was completed, a test screen appeared, and participants were asked to rate each test symbol or combination of symbols on the basis of the information provided during the preceding phase. Specifically, participants were asked to indicate the likelihood of the symbol or combination of symbols predicting the high red bar on a rating scale between 0 (very unlikely) and 9 (very likely) shown at the bottom of the screen. Again, the participants indicated their ratings by using the keyboard.

At the beginning of the experiment, all the participants were presented the first set of instructions shown in Appendix 1. The experiment was a $3 \times 3 \times 2$ design, where there were initially three conditions receiving different treatments: EXT/REC and EXT/NOREC conditions, which received nonreinforced trials of $\mathrm{X}$ during the extinction phase, and the control NOEXT/REC condition, which received nonreinforced trials of another CS, Y, during the extinction treatment. During the recovery phase, participants in the EXT/REC and NOEXT/REC conditions received nonreinforced $\mathrm{X}$-novel-CS trials, whereas those in the EXT/NOREC condition received nonreinforced trials of two novel CSs. All conditions were divided into two different groups according to the test stimulus they would be asked to rate at the end of each phase. Whereas conditioned inhibition (CI) groups were asked to rate excitors $(\mathrm{B}, \mathrm{G}$, and $\mathrm{H})$ paired with the conditioned inhibitor $\mathrm{X}$ (BX, GX, and HX), external inhibition (EI) groups were asked to rate excitors paired with novel CSs (BZ, GW, and HR). Therefore, there was a total of six groups: EXT/REC-CI, EXT/REC-EI, NOEXT/REC-CI, NOEXT/REC-EI, EXT/ NOREC-CI, and EXT/NOREC-EI. The ratings of CI and EI groups were compared in order to differentiate conditioned inhibition from external inhibition (see Melchers, Wolff, \& Lachnit, 2006; Rescorla, 1969).
During the acquisition phase, all the participants received $10 \mathrm{~A}+, 10 \mathrm{AX}-$, and $10 \mathrm{~B}+$ intermixed trials, as well as fillers, 10 reinforced compound trials, and 10 nonreinforced singleelement cue trials. After the inhibitory training, a summation test was conducted for all participants in order to measure the level of conditioned inhibition following the instructions shown in Appendix 2. During this test, the CI groups were asked to rate (on a 0 to 9 scale) B in compound with the conditioned inhibitor, $\mathrm{X}$, and the EI groups were asked to rate $\mathrm{B}$ in a compound with a novel cue, $\mathrm{Z}$.

During the extinction phase, the EXT/REC and EXT/ NOREC conditions were given $75 \mathrm{X}-$ and $10 \mathrm{G}+$ intermixed trials; cue $\mathrm{G}$ was used for the second summation test after the extinction phase. The NOEXT/REC condition was given 75 nonreinforced presentations of novel cue $\mathrm{Y}$, instead of $\mathrm{X}$ - presentations, intermixed with $10 \mathrm{G}+$ trials. Following the extinction phase, the second summation test was conducted with the new transfer cue, G. The CI groups were asked to rate GX, and the EI groups were asked to rate $\mathrm{G}$ with a novel cue, W.

During the recovery phase, another cue, $\mathrm{H}$, was trained as the predictor of the outcome. To recover the inhibition produced by $\mathrm{X}, \mathrm{X}$ was paired with a novel cue $\mathrm{N}$ without the outcome in the EXT/REC condition. Participants in the EXT/REC and NOEXT/REC conditions were shown five trials of $\mathrm{H}+$ and three trials of $\mathrm{XN}-$. Participants in the EXT/NOREC condition were shown five trials of $\mathrm{H}+$ and three trials of ML- (two novel CSs). Finally, the last summation test was conducted. Again, the CI groups rated HX, and EI groups rated $\mathrm{H}$ with a novel cue, $\mathrm{R}$.

\section{Results and discussion}

As is shown in the lower panel of Fig. 2, the experimental results closely match the predictions of the model for

Table 1 Experimental design of Experiment 1

\begin{tabular}{|c|c|c|c|c|c|c|c|}
\hline Conditions & Test groups & Acquisition & $\begin{array}{l}\text { Acquisition } \\
\text { summation test }\end{array}$ & Extinction & $\begin{array}{l}\text { Extinction } \\
\text { summation test }\end{array}$ & Recovery & $\begin{array}{l}\text { Recovery } \\
\text { summation test }\end{array}$ \\
\hline \multirow[t]{3}{*}{ Extinction recovery } & $C I$ & $10 \mathrm{~A}+$ & $1 \mathrm{BX}$ ? & $75 X-$ & $1 \mathrm{GX}$ ? & $3 \mathrm{XN}-$ & $1 \mathrm{HX}$ ? \\
\hline & EI & $10 \mathrm{AX}-$ & $1 \mathrm{BZ} ?$ & $10 \mathrm{G}^{+}$ & $1 \mathrm{GW} ?$ & $5 \mathrm{H}+$ & $1 \mathrm{HR}$ ? \\
\hline & & $10 \mathrm{~B}+$ & & $10 \mathrm{~F}+$ & & & \\
\hline \multirow[t]{3}{*}{ No-extinction recovery } & $C I$ & $10 \mathrm{CD}+$ & $1 \mathrm{BX}$ ? & $75 Y-$ & $1 \mathrm{GX}$ ? & $3 \mathrm{XN}-$ & $1 \mathrm{HX}$ ? \\
\hline & $E I$ & $10 \mathrm{E}-$ & $1 \mathrm{BZ} ?$ & $10 \mathrm{G}^{+}$ & $1 \mathrm{GW} ?$ & $5 \mathrm{H}+$ & $1 \mathrm{HR}$ ? \\
\hline & & & & $10 \mathrm{~F}+$ & & & \\
\hline \multirow[t]{3}{*}{ Extinction no-recovery } & $C I$ & & $1 \mathrm{BX}$ ? & $75 X-$ & $1 \mathrm{GX}$ ? & 3 ML- & $1 \mathrm{HX}$ ? \\
\hline & $E I$ & & $1 \mathrm{BZ} ?$ & $10 \mathrm{G}^{+}$ & $1 \mathrm{GW}$ ? & $5 \mathrm{H}+$ & $1 \mathrm{HR}$ ? \\
\hline & & & & $10 \mathrm{~F}+$ & & & \\
\hline
\end{tabular}

Note. Letters indicate different symbols. + means an outcome (red bar); - indicates the absence of the outcome 
summation tests in the different phases of the experiment. Following conditioned inhibition training (acquisition), the inhibitory CS decreased responding to a conditioned excitor in a summation test, but the inhibitory effect disappeared following repeated nonreinforced presentations (extinction) and reappeared following presentations of the inhibitory CS with a novel CS (recovery). Instead, when another CS was repeatedly not reinforced, the extinction treatment had no effect. Finally, when a CS (different from the CI) was paired with a novel CS, no recovery was observed in the summation test (however, such a procedure has an effect in a retardation test; see the Discussion section for Experiment 3). Figure 2 (lower panels) shows the mean ratings for the test trials of excitor with the conditioned inhibitor X, (BX, GX, and HX) and the excitor with a novel $\mathrm{CS}, \mathrm{BZ}, \mathrm{GW}$, and HR (test group: CI, or EI) for the EXT/ REC, NOEXT/REC, and EXT/NOREC conditions (condition) during three summation tests, after the acquisition, extinction, and recovery phases, respectively (phase). Eight participants were eliminated ( 5 in the EXT/REC-CI condition and 3 in the NOEXT/REC-CI condition) because they assigned a rating larger than 7 to the $\mathrm{BX}$ compound, which indicates that they did not acquire conditioned inhibition when compared with the responses to the $\mathrm{BZ}$ compound. Together with the 2 other participants eliminated due to program error, ratings from 120 participants were included in our statistical analysis.

A $3 \times 3 \times 2$ repeated measures ANOVA yielded a significant interaction between condition (EXT/REC vs. NOEXT/REC vs. EXT/NOREC), phase (acquisition vs. extinction vs. recovery), and test group (CI vs. EI), $F(4,226)=2.54, p=.041$. The aim of the following sections is to identify the source of the interaction between each condition.

EXT/REC and NOEXT/REC conditions A two-way ANOVA did not yield a significant interaction between test group (CI vs. EI) and condition (EXT/REC vs. NOEXT/ REC) for the acquisition phase, $F(1,76)=1.32, p=.254$, indicating that there was no significant difference between the levels of conditioned inhibition of these four groups. Additional two-tailed $t$ tests showed that both EXT/REC and NOEXT/REC conditions rated CI lower than EI, $t(38)=$ $3.38, p=.002$, and $t(38)=4.40, p<.001$, respectively. These results demonstrate that conditioned inhibition was learned by both groups during the acquisition phase.

After the extinction phase, a repeated measures ANOVA showed that a three-way interaction for the acquisition and extinction phases of test group (CI vs. EI), phase (acquisition vs. extinction), and condition (EXT/REC vs. NOEXT/REC) was significant, $F(1,76)=4.54, p=.036$. A two-way ANOVA yielded a significant interaction between test group (CI vs. EI) and condition for the extinction phase, $F(1,76)=11.81, p=.001$. This result indicates that
CI decreased in the EXT/REC condition, but not in the NOEXT/REC condition during the extinction phase. Furthermore, two separate repeated measures ANOVAs yielded a significant interaction between test group (CI vs. EI) and phase (acquisition vs. extinction phase) for the EXT/REC condition, $F(1,38)=14.35, p=.001$, while that interaction was not significant for the NOEXT/REC condition, $F(1,38)=1.09, p=.304$. Moreover, additional two-tailed $t$ tests showed that the participants in the NOEXT/REC condition, but not in the EXT/REC condition, rated CI lower than EI, $t(38)=3.64, p=.001$, and $t(38)=-1.04, p=.305$, respectively. These results demonstrate that $\mathrm{X}$ lost its inhibitory power after the extinction phase in the EXT/REC condition, but not in the NOEXT/REC condition.

Note that even when the ratings for both test groups were lower in the acquisition than in the extinction phase for the NOEXT/REC condition, the interaction between test group (CI vs. EI) and phase (acquisition vs. extinction phases) was not significant for that condition. This result was also predicted by the model as follows. The larger ratings after extinction in the NOEXT/REC condition are the consequence of the increased Novelty' and attention to the transfer excitor $\mathrm{H}$ used in the summation test because $\mathrm{Y}$ is absent but expected.

After the recovery phase, a repeated measures ANOVA showed that the three-way interaction of test group (CI vs. EI), phase (extinction vs. recovery phases), and condition was not significant, $F(1,76)=1.00, p=.320$. The interaction between test group (CI vs. EI) and condition (EXT/REC vs. NOEXT/REC) was not significant, $F(1,76)=2.68, p=.106$. Furthermore, after recovery, two-tailed $t$ tests showed that participants in both the EXT-REC and NOEXT/REC conditions rated CI lower than EI, $t(38)=2.36, p=.023$, and $t(38)=4.54, p<.001$, respectively. However, the interaction between test group (CI vs. EI) and phase (extinction and recovery phases) was significant for the EXT/REC condition, $F(1,38)=8.93, p=.005$, but not for the NOEXT/REC condition, $F(1,38)=2.84, p=.100$. These results demonstrate that the inhibition was recovered after the recovery phase for the EXT/REC condition, but it was not significantly increased for the NOEXT/REC condition.

EXT/REC and EXT/NOREC conditions A two-way ANOVA did not yield a significant interaction between test group (CI vs. EI) and condition (EXT/REC vs. EXT/ NOREC) for the acquisition phase, $F(1,72)=0.10$, $p=.748$, indicating that there was no significant difference between the levels of conditioned inhibition of these four groups. Additional two-tailed $t$ tests showed that participants in both the EXT/REC and EXT/NOREC conditions rated CI lower than EI, $t(38)=3.38, p=.002$, and $t(34)=$ $2.64, p=.012$, respectively. These results demonstrate that 
conditioned inhibition was learned by both groups during the acquisition phase.

After the extinction phase, a repeated measures ANOVA showed that a three-way interaction for the acquisition and extinction phases of test group (CI vs. EI), phase (acquisition vs. extinction), and condition (EXT/REC vs. EXT/NOREC) was not significant, $F(1,72)=0.61, p=.438$. A two-way ANOVA did not yield a significant interaction between test group (CI vs. $\mathrm{EI})$ and condition for the extinction phase, $F(1,72)=0.39$, $p=.532$. This result indicates that CI decreased in both the EXT/REC and EXT/NOREC conditions during the extinction phase.

After the recovery phase, a repeated measures ANOVA showed that the three-way interaction of test group (CI vs. EI), phase (extinction vs. recovery phases), and condition was significant, $F(1,72)=4.62, p=.035$. The interaction between test group (CI vs. EI) and phase (extinction and recovery phases) was significant for the EXT/REC condition, $F(1,38)=8.93, p=.005$, but not for the EXT/ NOREC condition, $F(1,34)=0.11, p=.747$. Furthermore, two-tailed $t$ tests showed that participants in the EXT/REC condition rated CI lower than EI, $t(38)=2.36, p=.023$, but not in the EXT/NOREC condition, $t(34)=0.82, p=.825$. These results demonstrate that the inhibition was recovered after the recovery phase for the EXT/REC condition, but not for the EXT/NOREC condition.

In sum, supporting the predictions of the SLG model, summation tests in Experiment 1 show that $\mathrm{X}$ was deactivated after nonreinforced trials. In addition, also supporting the predictions of the SLG model, Experiment 1 shows that $\mathrm{X}$, which had been deactivated after nonreinforced trials, was reactivated by pairing $\mathrm{X}$ with a novel stimulus. The three-way interaction is significant after the recovery phase because the EXT/REC, but not the EXT/NOREC, condition is affected by the treatment.

While at the end of the extinction phase, Experiment 1 indicates that $\mathrm{X}_{-}$trials result in a decreased inhibitory effect, thereby supporting the SLG model's prediction of a decreased attention $\mathrm{z}_{\mathrm{X}}$ and $\mathrm{X}_{\mathrm{X}}$, it is still possible that, as suggested by the Rescorla and Wagner (1972) model, the inhibitory association $\mathrm{V}_{\mathrm{X} \text {-US }}$ also decreases. However, the reinstated inhibition at the end of the recovery phase is consistent with the SLG model assumption that the $\mathrm{V}_{\mathrm{X}-\mathrm{US}}$ association had been preserved.

\section{Experiment 2: Retardation test following nonreinforced presentations of the conditioned inhibitor}

Along with the traditional view of conditioned inhibition (Rescorla, 1969), our model indicates that the inhibitory
$\mathrm{V}_{\mathrm{X} \text {-US }}$ association will (1) yield a reduced $\mathrm{CR}$ in a summation test, as well as (2) take longer to become excitatory than a neutral CS in a retardation test. In the previous section, we confirmed the model's prediction that the inhibitory effect of a CS in a summation test decreases after extended presentations that reduce $\mathrm{X}_{\mathrm{CS}}$, even if the inhibitory $\mathrm{V}_{\mathrm{CS}-\mathrm{US}}$ association does not change in the absence of the US. As was mentioned, because the model assumes that changes in $\mathrm{V}_{\mathrm{CS}-\mathrm{US}}$ are proportional to the magnitude of $X_{C S}$ (see Eq. 2), a decreased $X_{C S}$ results in slower changes of the $\mathrm{V}_{\mathrm{CS}-\mathrm{US}}$ association. Therefore, the model predicts that following extended presentation of an inhibitory CS, conditioning will be slow in a retardation test. This prediction, to be tested in Experiment 2, is in line with the decreased inhibitory effect of the CS, proportional to the product $\mathrm{X}_{\mathrm{CS}} \mathrm{V}_{\mathrm{CS}-\mathrm{US}}$ (see Eq. 1), shown in the summation test of Experiment 1.

Simulations for Experiment 2 consisted of $10 \mathrm{~A}+, 10$ $\mathrm{AX}-$, and $10 \mathrm{~B}+$ intermixed trials, followed by tests of $\mathrm{B}$, $\mathrm{BX}$, and $\mathrm{BZ}$, in which $\mathrm{Z}$ is a novel CS. Following the summation tests, the extinction condition received $75 \mathrm{X}-$ trials, and the no-extinction condition received $75 \mathrm{Y}-$ trials. The extinction phase was followed by a retardation test that included $3 \mathrm{X}+$ presentations intermixed with three reinforced presentations of J, a novel CS. Subsequently $\mathrm{X}$ and $\mathrm{J}$ were tested individually in the absence of the US. The upper panel of Fig. 4 shows that in a retardation test, conditioning of $\mathrm{X}$ is slower following $\mathrm{X}$ presentations, and responding reaches a lower value after a given number of trials. Importantly, that number of trials should be small enough to avoid reaching asymptotic responding.

Our simulations suggest that conditioning a $\mathrm{CI}$ in the extinction condition is retarded when compared with conditioning a novel CS, because $\mathrm{X}_{\mathrm{X}}$ is decreased after the repeated $\mathrm{X}$ - trials during the extinction phase (see Fig. 3, left panels). In addition, our simulations show that conditioning of a $\mathrm{CI}$ in the no- extinction condition is less retarded than that in the extinction condition, because $\mathrm{V}_{\mathrm{X}-\mathrm{US}}$ is inhibitory but $\mathrm{X}_{\mathrm{X}}$ is not decreased during the extinction phase (see Fig. 3, left panels). Experiment 2 was conducted to test these predictions.

Method

Participants The participants were 24 Duke University undergraduate students that had not taken part in any other experiment in this study. Their participation was rewarded with course credits. They were randomly assigned to two experimental groups.

Apparatus and stimuli The apparatus and stimuli were identical to those in Experiment 1. 


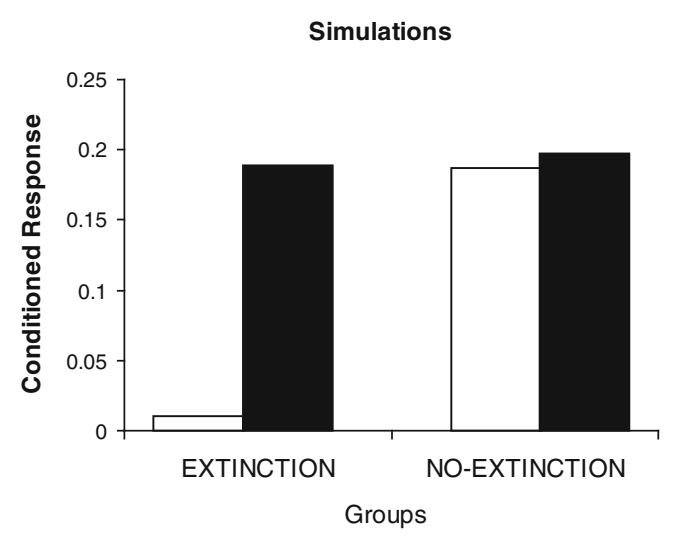

Experiment 2 - Retardation Test

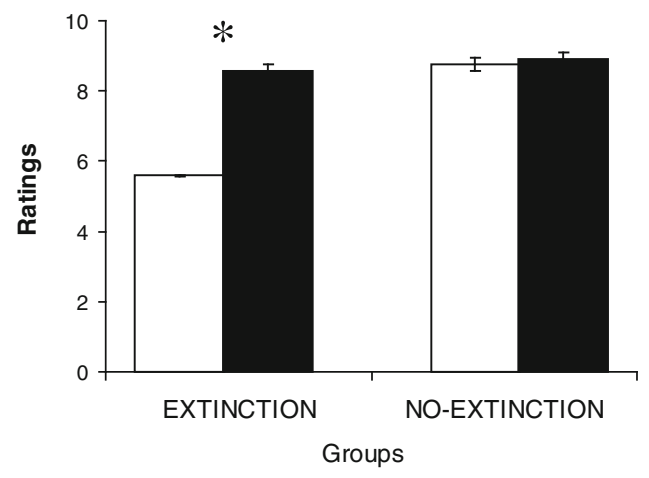

\section{$\square \mathrm{Cl} \square$ Novel CS}

Fig. 4 Experiment 2: Responses after conditioning trials of the conditioned inhibitor $(\mathrm{CI})$ and a novel $\mathrm{CS}$ in a retardation test following extinction or no extinction. Upper panel: Simulated conditioned responses to the $\mathrm{CI}$ and a novel CS, for extinction and no-extinction groups. Lower panel: Experimental ratings of CI and a novel CS, for extinction and no-extinction groups. Asterisks indicate a significant difference at the level of $p<.05$. Error bars show standard error of the mean $(S E M)$

Design and procedure Acquisition and extinction phases were identical to those in Experiment 1, except that instead of a summation test after the extinction phase, a retardation test was conducted (see Table 2). Ten F + trials during the extinction phase were kept as fillers. The first summation test, where the participants were asked to rate all stimuli (B, $\mathrm{BX}$, and $\mathrm{BZ}$ ), was run to verify that a significant level of conditioned inhibition was achieved. Escobar, Arcediano, and Miller (2003) successfully achieved retardation of a CS that was previously preexposed in a human predictive learning task without a masking task by using only a single acquisition trial and testing in the absence of the outcome. In line with this procedure, for the retardation test, first, one novel $\mathrm{CS}$, one $\mathrm{J}+$, and one $\mathrm{X}+$ trial were presented to the participants in order to condition $\mathrm{X}$ and $\mathrm{J}$. Then, after the retardation phase, the participants were asked to rate the novel CS and X only once. The order of the test trials was counterbalanced.

Results and discussion

After the acquisition phase, a repeated measures ANOVA did not yield a significant interaction between test stimuli (CI vs. EI) and condition (extinction vs. no-extinction), $F(1,22)=0.19, p=.666$, indicating no significant difference between the levels of conditioned inhibition in extinction and no- extinction conditions in the summation tests. Additional two-tailed $t$ tests showed that both conditions rated CI lower than EI, $t(11)=4.60, p=.001$, and $t(11)=5.30, p<.001$, respectively. These results show that conditioned inhibition was achieved for both groups during the acquisition phase.

Figure 4 (lower panels) shows the mean ratings for the retardation test of a novel $\mathrm{CS}$, J, and the conditioned inhibitor, $\mathrm{X}$, for extinction and no-extinction conditions after the extinction phase. After the extinction phase, a repeated measures ANOVA yielded a significant interaction between test stimuli (CI vs. novel CS) and condition, $F(1,22)=8.43, p=.008$, in the retardation tests. Two-tailed $t$ tests showed that participants in the extinction condition, but not in the no-extinction condition, rated the conditioned CI lower than the conditioned novel CS, $t(11)=3.12, p=.010$, and $t(11)=1.00, p=.339$, respectively. According to these analyses, the conditioned inhibitor $\mathrm{X}$ in the extinction
Table 2 Experimental design of Experiment 2

Note. Letters indicate different symbols. + means an outcome (red bar); - indicates the absence of the outcome

\begin{tabular}{llllll}
\hline Condition & Acquisition & $\begin{array}{l}\text { Acquisition } \\
\text { summation test }\end{array}$ & Extinction & Conditioning & Retardation test \\
\hline Extinction treatment & & & $75 \mathrm{X}-$ & \\
& $10 \mathrm{~A}+$ & & $10 \mathrm{~F}+$ & & \\
& $10 \mathrm{AX}-$ & $1 \mathrm{~B} ?$ & & $1 \mathrm{X}+$ & $\mathrm{X}+$ \\
& $10 \mathrm{~B}+$ & $1 \mathrm{BX} ?$ & & $\mathrm{~J} ?$ \\
& & $1 \mathrm{BZ} ?$ & $75 \mathrm{Y}-$ & \\
No-extinction treatment & $10 \mathrm{CD}+$ & & $10 \mathrm{~F}+$ & \\
& $10 \mathrm{E}-$ & & & & \\
\hline
\end{tabular}


condition showed significantly more retardation than did the novel CS, J. A similar result was reported by Pearce et al. (1982).

The data support the predictions of the model, suggesting that, after the extinction procedure, due to the decreased attention to $\mathrm{X}, \mathrm{X}$ in the extinction condition does not show inhibition in a summation test, but it shows retardation. In addition, the data also support the model's prediction (Fig. 4, upper panel) that retardation is not observed for $\mathrm{X}$ in the no- extinction condition, due to the fast learning (one reinforced trial) that occurs in a predictive learning preparation (Escobar et al., 2003). Passing the retardation test would have excluded the possibility that $\mathrm{X}$ had modified attention to the excitatory CS, thereby attenuating responding. This possibility has already been excluded in Experiment 1, in which the inhibitory power of $\mathrm{X}$ was stronger than that of external inhibitor (EI), a result the rules out alternative attentional explanations.

Also note that whereas, in our simulations, the number of conditioning trials in the retardation test consisted of three novel $\mathrm{CS}+$ and three $\mathrm{X}+$, the experiment used only one novel $\mathrm{CS}+$ and one $\mathrm{X}^{+}$, due to the fast learning in this preparation (see Escobar et al., 2003).

\section{Experiment 3: Retardation test following recovery of the conditioned inhibitor}

As has been mentioned, the model predicts that after extended nonreinforced $\mathrm{X}$ presentations, presenting the inhibitory $\mathrm{X}$ with a novel $\mathrm{CS}_{\mathrm{N}}$ before testing will increase attention to the inhibitor when (1) the inhibitory $X$ is presented together with the novel $\mathrm{CS}, \mathrm{N}$, and (2) the inhibitory $\mathrm{X}$ is later tested in the absence of that novel CS, $\mathrm{N}$. According to the model, the increased $\mathrm{X}_{\mathrm{CS}}$ will result in a reinstated inhibition (as shown in the summation test of Experiment 1) and a decreased retardation. The retardation prediction was tested in Experiment 3.

Simulations for Experiment 3 consisted of $10 \mathrm{~A}+, 10$ $\mathrm{AX}-$, and $10 \mathrm{~B}+$ intermixed trials, followed by tests of $\mathrm{B}, \mathrm{BX}$, and $\mathrm{BZ}$, in which $\mathrm{Z}$ was a novel CS. Following these tests, both recovery and no-recovery conditions received 75 extinction $\mathrm{X}$ - trials. The extinction phase was followed by a recovery phase. In the recovery condition, three trials of $\mathrm{X}$ with a novel CS, N, were given, while the no-recovery condition received three trials of $\mathrm{CX}$ alone preceding conditioning (three $\mathrm{X}+$ trials alternated with three $\mathrm{J}+$ trials), and a test phase (one $\mathrm{X}$ - trial and one $\mathrm{J}-$ trial). The upper panel of Fig. 5 shows that the inhibitory power of $\mathrm{X}$ was reinstated after presentations of $\mathrm{X}$ with a novel stimulus $\mathrm{N}$ in the recovery condition, while $\mathrm{X}$ in the no-recovery condition was retarded. In order to measure the initial inhibitory

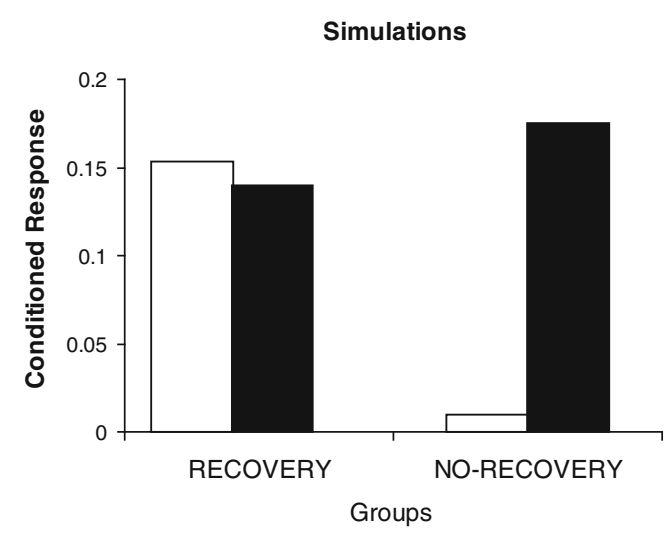

Experiment 3 - Retardation Test

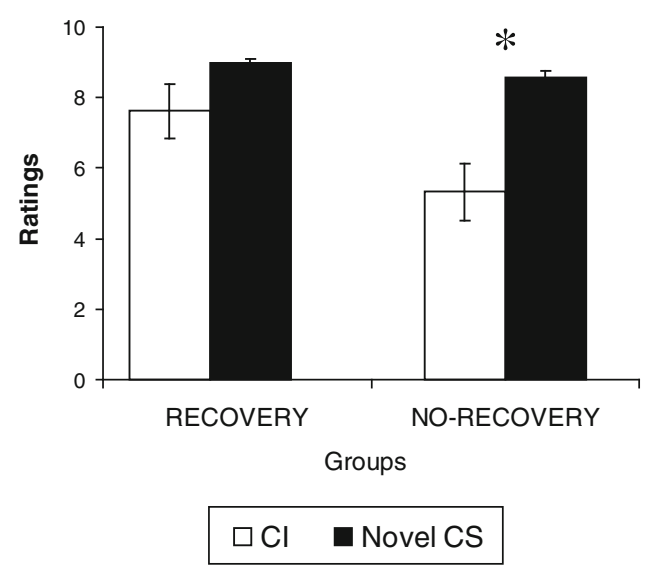

Fig. 5 Experiment 3: Responses after conditioning of the conditioned inhibitor (CI) and a novel CS in a retardation test following recovery and no-recovery treatments. Upper panel: Simulated conditioned responses to the $\mathrm{CI}$ and a novel CS, for recovery and no-recovery conditions. Lower panel: Experimental ratings for the CI and a novel $\mathrm{CS}$, for extinction and no-extinction groups. Error bars show standard error of the mean (SEM)

level of $\mathrm{X}$, a summation test was given after the acquisition phase. Our simulations suggest that $\mathrm{X}_{\mathrm{X}}$ decreases with repeated $\mathrm{X}$ - trials and increases during the recovery treatment (see Fig. 3). Therefore, the model predicts that the retardation shown by $\mathrm{X}$ after extinction can be reversed by increasing attention to $\mathrm{X}$ during a recovery phase.

Simulations for the no-recovery condition received three trials of CX alone, because the model predicts that when two novel stimuli (ML) are used in the control condition to replace $\mathrm{X}$ and $\mathrm{N}$, as in Experiment 1, attention to $\mathrm{X}$ increases during retardation. This is a consequence of Novelty' being relatively large when $\mathrm{M}$ and L are absent but predicted by the context. This increase in attention would be enough to eliminate retardation in the no-recovery control group, which would behave like the recovery group. Note, however, that the same increase in attention did not 
eliminate the effect of extinction of $\mathrm{X}$ in the summation test in the EXT/NOREC group in Experiment 1. According to the model, in Experiment 1, Novelty' and $X_{X}$ increase less in the EXT/NOREC group than in the EXT/REC group (see the "Recovery" columns in Fig. 3) and, therefore, have no effect on the extinguished $\mathrm{X}$ in the summation test (see Eq. 1). However, the model indicates that in the norecovery group in Experiment 3, this small increase in $X_{X}$ would have a prolonged effect during the duration of conditioning (see Eq. 2) that would eliminate the difference with the recovery group.

Method

Participants The participants were 24 Duke University undergraduate students who had not taken part in any other experiment in this study. Their participation was rewarded with course credits. They were randomly assigned to two experimental conditions.

Apparatus and stimuli The apparatus and stimuli were identical to those in Experiment 1.

Design and procedure In Experiment 3, acquisition, extinction, and retardation test phases were identical to those in Experiment 2, except this time, as in Experiment 1, a recovery or no-recovery phase was added before the retardation test (see Table 3). As in Experiment 2, we kept the first summation test, where the participants were asked to rate all stimuli ( $\mathrm{B}, \mathrm{BX}$, and $\mathrm{BZ}$ ), to verify that a significant level of conditioned inhibition was achieved. There were two conditions, recovery and no recovery. During the recovery phase, $\mathrm{X}$ was paired with a novel cue $\mathrm{N}$ without the outcome for the recovery condition Participants in this condition were shown three trials of $\mathrm{XN}-$. For the no-recovery condition, participants were shown only the context, which was the white screen where the symbols were presented for the duration of three trials $(6 \mathrm{~s})$. As was mentioned above, exposure to the context (instead of exposure to ML) was used in the no-recovery condition, because the model predicts that if two stimuli (ML) are used in the control condition, attention to $\mathrm{X}$ increases during retardation. After the recovery phase, the retardation test consisted of one novel $\mathrm{CS}+$ and one $\mathrm{X}+$. Then participants were asked to rate the novel CS and X. The order of the test trials was counterbalanced.

Results and discussion

After the acquisition phase, a repeated measures ANOVA showed no significant interaction between test stimuli (CI vs. EI) and condition (recovery vs. no recovery), $F(1,22)=$ $0.7, p=.414$, in the summation test following the acquisition phase. Two-tailed $t$ tests showed both conditions rated CI lower than EI $[t(11)=5.23, p<.001$, for the recovery condition, and $t(11)=6.42, p<.001$, for the norecovery condition]. These results show that conditioned inhibition was equally achieved by both groups during the acquisition phase.

Figure 5 (lower panels) shows the mean ratings for the retardation test of a novel $\mathrm{CS}, \mathrm{J}$, and the conditioned inhibitor, $\mathrm{X}$ for the recovery and no-recovery conditions subsequent to the recovery phase.

Following the recovery phase, a repeated measures ANOVA showed that the interaction between test stimuli (CI vs. novel CS) and condition (recovery vs. no recovery) was significant, $F(1,22)=7.75, p=.011$, after the retardation test. Furthermore, two-tailed $t$ tests showed that in the no-recovery condition, there was a significant difference between CI and novel CS ratings, $t(11)=4.00$, $p=.002$, but not in the recovery condition, $t(11)=1.91$, $p=.082$. Overall, these results show that the inhibitory power of $\mathrm{X}$ is recovered in the recovery condition, but not in the no-recovery condition. That is, the recovery treatment reinstates attention to $\mathrm{X}$, which now conditions faster in the retardation test.

In sum, Experiment 3 supported the predictions of the model that even though $\mathrm{X}$ shows inhibition when it is tested in a summation test after a recovery phase (Experiment 1), it shows less retardation due to its increased attention when it is compared with a novel CS. As was discussed above, the $\mathrm{CI}$ in the recovery condition shows no retardation, even
Table 3 Experimental design of Experiment 3

Note. Letters indicate different symbols. + means an outcome (red bar); - indicates the absence of the outcome

\begin{tabular}{lllllll}
\hline Condition & Acquisition & $\begin{array}{l}\text { Acquisition } \\
\text { summation test }\end{array}$ & Extinction & Recovery & Conditioning & $\begin{array}{c}\text { Retardation } \\
\text { test }\end{array}$ \\
\hline $\begin{array}{c}\text { Recovery } \\
\text { treatment }\end{array}$ & $\begin{array}{l}10 \mathrm{~A}+ \\
10 \mathrm{AX}-\end{array}$ & $\begin{array}{l}1 \mathrm{~B} ? \\
10 \mathrm{~B}+\end{array}$ & $\begin{array}{l}1 \mathrm{BX} ? \\
1 \mathrm{BZ} ?\end{array}$ & $75 \mathrm{X}-$ & & $3 \mathrm{XN}-$ \\
& & $10 \mathrm{~F}+$ & & $1 \mathrm{X}+$ & $\mathrm{X} ?$ \\
$\begin{array}{c}\text { No-recovery } \\
\text { treatment }\end{array}$ & $10 \mathrm{CD}+$ & & & 3 Context- & $\mathrm{J} ?$ \\
\hline
\end{tabular}


when they are initially inhibitory, due to the fast conditioning that takes place in our preparation. Again, even if $\mathrm{X}$ does not pass the retardation test in this condition, it shows more inhibitory power than an EI in the summation test of Experiment 1. Note, however, that as in Experiment 2, we used only one novel $\mathrm{CS}+$ and one $\mathrm{X}+$ trial.

\section{General discussion}

The present study confirmed the SLG model's prediction that extended nonreinforced presentations of a conditioned inhibitor results in a decreased inhibitory power in a summation test (Experiment 1) but in an increased effect in a retardation test (Experiment 2). Furthermore, in agreement with the model's predictions, presentations of the "extinguished" inhibitor with a novel stimulus before testing restored its inhibitory behavior in a summation test (Experiment 1) but accelerated its conditioning in a retardation test (Experiment 3). According to the model, these results are explained in terms of (1) the decreased attention to the inhibitory CS during nonreinforced trials and (2) the increased attention to the inhibitory CS following a few presentations of that CS with a novel CS (see Fig. 3). In other words, whereas extended nonreinforced presentations of the inhibitory CS decreases $\mathrm{X}_{\mathrm{CS}}$ and results in less inhibition in a summation test (Experiment 1) and increased retardation (Experiment 2), presentation of the inhibitory CS with a novel CS before testing increases $\mathrm{X}_{\mathrm{CS}}$ and results in more inhibition in a summation test (Experiment 1) but decreased retardation (Experiment 3).

Note that our explanation of increased retardation following $X_{-}$presentations is similar to the model's explanation of data showing that prolonged extinction of an excitor results in slower reacquisition (Bouton, 1986; Bouton \& Swartzentruber, 1989; Ricker \& Bouton, 1996) and of latent inhibition (Schmajuk et al., 1996). Another, related result, also explained in attentional terms, is the finding that responding decreases with extended conditioning (Heth, 1976). Similarly, Pearce et al. (1982) indicated that exposure of $\mathrm{X}_{-}$"may have had an effect analogous to that found in latent inhibition." In all cases, the SLG model explains these results in terms of decrements in attention with repeated CS presentations with or without the US.

Our results add to the number of classical conditioning paradigms that the SLG model correctly describes, including latent inhibition (Schmajuk, Gray, \& Larrauri, 2005; Schmajuk \& Kutlu, 2011), recovery from blocking and overshadowing (Schmajuk \& Larrauri, 2006), the effects of compound conditioning of CSs with different initial associative values (Schmajuk, 2009), and the multiple properties of extinction (Larrauri \& Schmajuk, 2008).
Predictions of the model

Note that simulation trials exactly match the number of experimental trials in all cases except for the conditioning procedure preceding the retardation tests in Experiments 2 and 3 , in which the model uses three $\mathrm{X}+$ trials and the experiment only one $\mathrm{X}+$ trial. This difference should not be surprising, because the SLG model is a "generic" model of classical conditioning whose parameters do not apply to any specific species or preparation. These parameters determine that at least three $\mathrm{X}+$ trials are needed to reach a level of learning that allows us to appreciate any difference in retardation between groups. Because conditioning is fast in humans, three $\mathrm{X}+$ trials result in asymptotic learning independently of the rate of acquisition. Therefore, retardation tests used only one $\mathrm{X}+$ trial that, by avoiding saturation, shows differences in the final value of conditioning. Note that the important predictions of the model refer to the extinction and recovery effects of inhibition, not to the number of trials used in the retardation tests.

Importantly, all our predictions are based on mathematical properties of the model, independently of species and preparation, and are valid for a wide range of simulation values. Because $X_{X}$ decreases with repeated presentations, the inhibitor will be less effective in reducing responding in summation tests according to Eq. 1. Similarly, a decreased $\mathrm{X}_{\mathrm{X}}$ will result in increased retardation according to Eq. 2 . Therefore, the same simulation results are obtained for a large range of acquisition, extinction, and recovery trials.

Comparison with other experimental results

Like Zimmer-Hart and Rescorla (1974), a number of studies (Detke, 1991; De Vito \& Fowler, 1986, 1987; Lysle \& Fowler, 1985; Rescorla, 1982; Williams, 1986; Williams \& Overmier, 1988; Witcher \& Ayres, 1984) reported that extinction treatment of a conditioned inhibitor results in no change in its inhibitory properties as shown by a summation test. Similarly, Pearce et al. (1982) showed no effect of the treatment summation test, but importantly, they reported increased retardation. In contrast, other studies (Holland, 1985; Holland \& Gory, 1986; Rescorla, 1982; Williams et al., 1986) reported increased inhibition in a summation test.

In a human contingency learning experiment, Melchers et al. (2006; Lotz \& Lachnit, 2009) found that presentations of the inhibitory CS results in the extinction of its inhibitory properties in a summation test when the outcome (equivalent to an US) takes both positive and negative values but, like the above-mentioned studies, found no effect when the US takes only positive values. Also, using a human contingency learning task, Baetu 
and Baker (2010) reported extinction of the conditioned inhibitor either when the outcome takes positive and negative values or when it takes positive values alone. In contrast, using the same task, Yarlas, Cheng, and Holyoak (1995) found no effect of extinction.

Kutlu and Schmajuk (2011) applied the SLG model to explain some of the contradictory results mentioned in the Introduction. According to the model, Zimmer-Hart and Rescorla's (1974) results reporting no effect in a summation test are explained as follows. In the experimental group, the conditioned inhibitor is well predicted by the context after receiving extinction treatment in that context, but not in the control group that receives exposure only to the context. Therefore, during the summation test, the inhibitor is well predicted, and Novelty' is relatively low in the experimental group, but large in the control group. As a consequence, attention to both the inhibitor and the transfer excitatory stimulus are relatively small in the experimental group and relatively large in the control group. Therefore, because the excitatory power of the inhibitor and the excitor are decreased in the experimental group, but not in the control group, similar differences between responding to the excitor and excitor-inhibitor compound are observed in both groups.

According to the model, Pearce et al.'s (1982) Experiment 1 results reporting no effect in a summation test are explained like Zimmer-Hart and Rescorla's (1974) data. Pearce et al.'s Experiment 3 results reporting increased retardation are explained in terms of the decreased attention to the conditioned inhibitor in the experimental group, but not in the control group. In this case, the decreased attention of the inhibitor does not affect the effectiveness of the reinforcing US, in contrast to the summation test of Experiment 1, in which it decreases attention to the transfer excitatory stimulus.

Williams et al.'s (1986) Experiment 4 results reporting increased inhibition in a summation test are explained as follows. In Zimmer-Hart and Rescorla's (1974) Experiment 1 and Pearce et al.'s (1982) Experiment 1, the transfer stimulus was reinforced before the extinction treatment of the inhibitor. By contrast, in Williams et al.'s Experiment 4, the transfer stimulus was trained following the nonreinforced presentations of the inhibitor in the context, which resulted in the formation of strong $\mathrm{CX}-\mathrm{X}$ associations. Therefore, even if $\mathrm{Z}_{\mathrm{X}}$ decreases during extinction, $\mathrm{Z}_{\mathrm{X}}$ increases again when the transfer stimulus is trained and the prediction of $\mathrm{X}, \mathrm{B}_{\mathrm{X}}$, is activated through the $\mathrm{CX}-\mathrm{X}$ association (see Fig. 1), thereby increasing inhibition during the summation test.

Finally, the present results and those reported by Baetu and Baker (2010) showing that presentations of the inhibitor results in the extinction of its power in a summation test can possibly be explained by the strong decremental effect of nonreinforced trials on $\mathrm{z}_{\mathrm{X}}$ and $\mathrm{X}_{\mathrm{X}}$ in human contingency learning, which cannot be compensated for by a decrease in attention to the transfer excitatory CS, as in the Zimmer-Hart and Rescorla (1974) and Pearce et al. (1982) studies. Supporting this interpretation, loss of inhibitory power of the inhibitor was found in rats (Ralph Miller, personal communication) following extended (300) nonreinforced presentations of the inhibitor. Interestingly, computer simulations with our model show that the effect of nonreinforced presentations of the inhibitor is relatively weak when, as in Melchers et al.'s (2006) study, inhibition of the same stimulus is measured in two summation tests, one before and the other after the extinction trials. According to the model, the first summation test causes Novelty' to increase during extinction, which results in a weaker decremental effect of nonreinforced trials on $z_{X}$ and $\mathrm{X}_{\mathrm{X}}$ and a stronger inhibition in the second summation test.

\section{Importance for the SLG model explanation of extinction}

The present results also support the model's prediction that during extinction, the context $\mathrm{CX}$ becomes inhibitory when presented with the initially excitatory CS in the absence of the US (Larrauri \& Schmajuk, 2008). Recently Polack, Laborda, and Miller (2011) confirmed that contexts can acquire inhibitory properties during extinction. However, Bouton and Swartzentruber (1989, Experiment 3) and Bouton and King (1983, Experiment 4) have argued against this view, because it seems to contradict their data showing that no CX-US inhibitory associations are detected in a summation test. Nevertheless, Larrauri and Schmajuk showed that the SLG model explains those results, because attention to the $\mathrm{CX}$ decreases during extinction trials, thereby making the inhibitory CX-US associations undetectable. The present article demonstrates the plausibility of this suggestion by supporting the notion that repeated presentations decrease attention to the inhibitor and deactivate its inhibitory power in a summation test.

As shown by Larrauri and Schmajuk (2008), the notion of the context becoming inhibitory but unattended during extinction plays a crucial role in the model explanation of phenomena such as spontaneous recovery. According to the model, spontaneous recovery is explained in terms of (1) a decreased attention to both the excitatory CS and the inhibitory CX during extinction, (2) a fast increase in attention to the partly preserved excitatory CS when it is tested after a period of time in which CX-CS associations are extinguished, and (3) a slow increase in attention to the inhibitory CX during testing. Combination of (1) and (2) yields the temporary increased responding that characterizes spontaneous recovery. In addition, by supporting the idea that the context becomes inhibitory, our data also support the model's description of renewal (the inhibitory context is removed and responding 
reappears) and reinstatement (the inhibitory associations of the context are eliminated and responding reappears).

Alternative theories

Some associative theories address the results presented in this article. As indicated by Baetu and Baker (2010), extinction of a conditioned inhibitor is consistent with the Rescorla and Wagner (1972) associative model. However, the fact that inhibition can be reinstated following the presentation of the extinguished inhibitory CS with a novel (nonexcitatory) CS suggests that nonreinforced presentations decrease attention to the conditioned inhibitor but does not eliminate the inhibitory association. This result is inconsistent with the Rescorla-Wagner model.

According to the SOP model (Wagner, 1981), inhibition is the result of the target CS acquiring inhibitory associations with the US when presented with the excitatory CS in the absence of the US. Although an extinction treatment does not decrease the inhibitory CS-US associations, the treatment results in the strengthening of CX-inhibitory-CS associations, thereby moving the inhibitor from the A1 state to the A2 state. State A2 is less effective in activating of the association of the inhibitory CS during summation tests and increases retardation during conditioning.

Even if SOP can describe the results of the nonreinforced presentation of the inhibitory CS, the model cannot describe the inhibition being "reinstated" by the absence of the novel CS during testing. According to the model, strong $\mathrm{CX}$-inhibitory-CS associations are formed during the extended extinction phase and block the formation of novel CS-inhibitory-CS associations. Therefore, the inhibitory CS will be perfectly predicted by the CX during testing, thereby being unable to enter the A1 state.

According to the comparator hypothesis (Stout \& Miller, 2007), inhibition is the result of the target CS having a lower expectation of the US than its comparator, the excitatory CS. Therefore, nonreinforced presentations of the inhibitory CS would eliminate its association with the excitatory $\mathrm{CS}$, thereby decreasing its inhibitory value. It is unclear how the model would predict reinstatement.

Finally, and as indicated by Baetu and Baker (2010), our results are inconsistent with inferential theories of learning (De Houwer, Beckers, \& Vandorpe, 2005). According to these views, just as people do not think that aspirin loses its antipyretic effects when taken in the absence of fever, inferential theories expect that $\mathrm{X}$ does not lose its inhibitory power during the extinction phase.

In sum, it seems that our model is the only one at present capable of explaining the results presented in this study.
Appendix 1 Experimental instructions at the beginning of the experiments

"In this experiment you will be shown one or two symbols at a time. These symbols predict either a HIGH BAR or a LOW BAR. Your task is to learn which symbols predict a HIGH BAR and which ones predict a LOW BAR. To do that, you need to guess whether the symbols predict the HIGH bar or not, by pressing " $\mathrm{H}$ " for the high bar and " $\mathrm{L}$ " for the low bar on your keyboard. On each trial, the computer will display one or two symbols and a red bar: HIGH BAR or LOW BAR. You will be shown the information in 3 separate parts. After each part, you will have to judge how likely the symbols predict a "HIGH BAR". In this task it is imperative that you are as accurate as possible. *Press the space bar to continue. $*$

\section{Appendix 2 Experimental instructions for the summation and retardation tests}

"Now you have to indicate how likely the symbols are to predict a HIGH BAR. You have to judge on a rating scale ranging from 0 (the symbols are very unlikely to predict a HIGH BAR) to 9 (the symbols are very likely to predict a HIGH BAR), using the keyboard numbers from 0 to 9 . $*$ Press the space bar to continue."”

\section{References}

Baetu, I., \& Baker, A. G. (2010). Extinction and blocking of conditioned inhibition in human causal learning. Learning \& Behavior, 38, 394-407.

Baker, A. G. (1974). Conditioned inhibition is not the symmetrical opposite of conditioned excitation: A test of the Rescorla-Wagner model. Learning and Motivation, 5, 396-379.

Bouton, M. E. (1986). Slow reacquisition following the extinction of conditioned suppression. Learning and Motivation, 17, 1-15.

Bouton, M. E., \& King, D. A. (1983). Contextual control of the extinction of conditioned fear: Tests for the associative value of the context. Journal of Experimental Psychology. Animal Behavior Processes, 9, 248-265.

Bouton, M. E., \& Swartzentruber, D. (1989). Slow reacquisition following extinction: Context, encoding, and retrieval mechanisms. Journal of Experimental Psychology. Animal Behavior Processes, 15, 43-53. 
De Houwer, J., Beckers, T., \& Vandorpe, S. (2005). Evidence for the role of higher order reasoning processes in cue competition and other learning phenomena. Learning \& Behavior, 33, 239-249.

De Vito, P. L., \& Fowler, H. (1986). Effects of contingency violations on the extinction of a conditioned fear inhibitor and a conditioned fear excitor. Journal of Experimental Psychology. Animal Behavior Processes, 12, 99-115.

De Vito, P. L., \& Fowler, H. (1987). Enhancement of conditioned inhibition via an extinction treatment. Animal Learning \& Behavior, 15, 448-454.

Detke, M. J. (1991). Extinction of sequential conditioned inhibition. Animal Learning \& Behavior, 19, 345-354.

Escobar, M., Arcediano, F., \& Miller, R. R. (2003). Latent inhibition in human adults without masking. Journal of Experimental Psychology. Learning, Memory, and Cognition, 29, 1028-1040.

Heth, C. D. (1976). Simultaneous and backward fear conditioning as a function of number of CS-UCS pairings. Journal of Experimental Psychology. Animal Behavior Processes, 2, 117-129.

Holland, P. C. (1985). The nature of conditioned inhibition in serial and simultaneous feature negative discriminations. In R. R. Miller \& N. E. Spear (Eds.), Information processing in animals: Conditioned inhibition (pp. 267-297). Hillsdale: Erlbaum.

Holland, P. C., \& Gory, J. (1986). Extinction of inhibition after serial and simultaneous feature negative discrimination training. Quarterly Journal of Experimental Psychology, 38B, 245-265.

Karazinov, D. M., \& Boakes, R. A. (2004). Learning about cues that prevent an outcome: Conditioned inhibition and differential inhibition in human predictive learning. Quarterly Journal of Experimental Psychology, 57B, 153-178.

Kutlu, M. G., \& Schmajuk, N. A. (2011). Attentional and associative mechanisms in conditioned inhibition. Manuscript submitted for publication.

Larrauri, J. A., \& Schmajuk, N. A. (2008). Attentional, associative, and configural mechanisms in extinction. Psychological Review, $115,640-676$.

Lotz, A., \& Lachnit, H. (2009). Extinction of conditioned inhibition: Effects of different outcome continua. Learning \& Behavior, 37, $85-94$.

Lysle, D. T., \& Fowler, H. (1985). Inhibition as a "slave" process: deactivation of conditioned inhibition through extinction of conditioned excitation. Journal of Experimental Psychology: Animal Behavior Processes, 11, 71-94.

McLaren, I. P. L., Kaye, H., \& Mackintosh, N. J. (1989). An associative theory of the representation of stimuli: Applications to perceptual learning and latent inhibition. In R. G. M. Morris (Ed.), Parallel distributed processing: Implications for psychology and neurobiology (pp. 102-130). Oxford: Oxford University Press, Clarendon Press.

McLaren, I. P. L., \& Mackintosh, N. J. (2000). An elemental model of associative learning: I. Latent inhibition and perceptual learning. Animal Learning \& Behavior, 28, 211-246.

McLaren, I. P. L., \& Mackintosh, N. J. (2002) Associative learning and elemental representation: II. Generalization and discrimination. Animal Learning \& Behavior, 30, 177-200.

Melchers, K. G., Wolff, S., \& Lachnit, H. (2006). Extinction of conditioned inhibition through nonreinforced presentation of the inhibitor. Psychonomic Bulletin \& Review, 13, 662-667.

Pavlov, I. P. (1927). Conditioned Reflexes. London: Oxford University Press.

Pearce, J. M., \& Hall, G. (1980). A model for Pavlovian learning: Variations in the effectiveness of conditioned but not of unconditioned stimuli. Psychological Review, 87, 532-552.

Pearce, J. M., Nicholas, D. J., \& Dickinson, A. (1982). Loss of associability by a conditioned inhibitor. Quarterly Journal of Experimental Psychology, 34B, 149-162.
Polack, C., Laborda, M., Miller, R. R. (2011). Extinction context as a conditioned inhibitor. Learning \& Behavior [Electronic publication ahead of print].

Rescorla, R. A. (1969). Pavlovian conditioned inhibition. Psychological Bulletin, 72, 77-94.

Rescorla, R. A. (1982). Some consequences of associations between the excitor and the inhibitor in a conditioned inhibition paradigm. Journal of Experimental Psychology. Animal Behavior Processes, 8, 288-298.

Rescorla, R. A., \& Wagner, A. (1972). A theory of Pavlovian conditioning: Variations in the effectiveness of reinforcement and non-reinforcement. In A. H. Black \& W. F. Prokasy (Eds.), Classical conditioning II: Current research and theory (pp. 64-99). New York: Appleton-Century-Crofts.

Ricker, S. T., \& Bouton, M. E. (1996). Reacquisition following extinction in appetitive conditioning. Animal Learning \& Behavior, 24, 423-436.

Schmajuk, N. A. (2009). Attentional and error-correcting associative mechanisms in classical conditioning. Journal of Experimental Psychology. Animal Behavior Processes, 35, 407-418.

Schmajuk, N. A., Gray, J. A., \& Larrauri, J. A. (2005). A pre-clinical study showing how dopaminergic drugs administered during pre-exposure can impair or facilitate latent inhibition. Psychopharmacology, 177, $272-279$.

Schmajuk, N. A., \& Kutlu, M. G. (2011). Latent inhibition and compound conditioning: A reply to Holmes and Harris (2009). Journal of Experimental Psychology. Animal Behavior Processes, 37, 254-260.

Schmajuk, N. A., Lam, Y., \& Gray, J. A. (1996). Latent inhibition: A neural network approach. Journal of Experimental Psychology. Animal Behavior Processes, 22, 321-349.

Schmajuk, N. A., \& Larrauri, J. A. (2006). Experimental challenges to theories of classical conditioning: Application of an attentional model of storage and retrieval. Journal of Experimental Psychology. Animal Behavior Processes, 32, 1-20.

Schmajuk, N. A., Larrauri, J. A., \& LaBar, K. S. (2007). Reinstatement of conditioned fear and the hippocampus: An attentional-associative model. Behavioural Brain Research, 177, 242-253.

Stout, S. C., \& Miller, R. R. (2007). Sometimes-competing retrieval (SOCR): A formalization of the comparator hypothesis. Psychological Review, 114, 759-783.

Wagner, A. R. (1981). SOP: A model of automatic memory processing in animal behavior. In N. E. Spear \& R. R. Miller (Eds.), Information processing in animals: Memory mechanisms (pp. 5-47). Hillsdale: Erlbaum

Williams, D. A. (1986). On extinction of inhibition: Do explicitly unpaired conditioned inhibitors extinguish? The American Journal of Psychology, 99, 515-525.

Williams, D. A., \& Overmier, J. B. (1988). Some types of conditioned inhibitors carry collateral excitatory associations. Learning and Motivation, 19, 345-368.

Williams, D. A., Travis, G. M., \& Overmier, J. B. (1986). Within-compound associations modulate the relative effectiveness of differential and Pavlovian conditioned inhibition procedures. Journal of Experimental Psychology. Animal Behavior Processes, 12, 351-362.

Witcher, E. S., \& Ayres, J. J. B. (1984). A test of two methods for extinguishing Pavlovian conditioned inhibition. Animal Learning \& Behavior, 12, 149-156.

Yarlas, A. S., Cheng, P. W., \& Holyoak, K. J. (1995). Alternative approaches to causal induction: The probabilistic contrast versus the Rescorla-Wagner model. In J. D. Moore \& J. F. Lehman (Eds.), Proceedings of the seventeenth annual conference of the cognitive science society (pp. 431-436). Hillsdale: Erlbaum.

Zimmer-Hart, C. L., \& Rescorla, R. A. (1974). Extinction of Pavlovian conditioned inhibition. Journal of Comparative and Physiological Psychology, 86, 837-845. 